City University of New York (CUNY) CUNY Academic Works

\title{
Biological Research on Burnout-Depression Overlap: Long- Standing Limitations and On-going Reflections
}

Renzo Bianchi

Université de Neuchâtel

Irvin Sam Schonfeld

cUNY Graduate Center

Eric Laurent

Université Bourgogne - Franche-Comté

\section{How does access to this work benefit you? Let us know!}

More information about this work at: https://academicworks.cuny.edu/gc_pubs/470

Discover additional works at: https://academicworks.cuny.edu

This work is made publicly available by the City University of New York (CUNY).

Contact: AcademicWorks@cuny.edu 
Discussion

\title{
Biological research on burnout-depression overlap: Long-standing limitations and on-going reflections
}

\author{
Renzo Bianchi $^{\mathrm{a}, *}$, Irvin Sam Schonfeld ${ }^{\mathrm{b}}$, Eric Laurent ${ }^{\mathrm{c}}$ \\ a University of Neuchâtel, Institute of Work and Organizational Psychology, Neuchâtel, NE, Switzerland \\ b The City College of the City University of New York, Department of Psychology, New York City, NY, United States



\section{A R T I C L E I N F O}

\section{Keywords:}

Burnout

Depression

Diagnosis

Methodology

Nosology

\begin{abstract}
A B S T R A C T
In this commentary, we discuss seldom-noticed methodological problems affecting biological research on burnout and depression and make recommendations to overcome the limitations of past studies conducted in this area. First, we suggest that identified subtypes of depression (e.g., depression with melancholic features and depression with atypical features) should be taken into account in future biological research on burnout and depression, given that different subtypes of depression have been associated with distinct autonomic and neuroendocrine profiles. Second, we underline that research on burnout-depression overlap is made difficult by the absence of a consensual conceptualization and operationalization of burnout. In order to resolve this problem, we draw researchers' attention to the urgency of establishing a commonly shared, clinically valid diagnosis for burnout. Finally, we question the possibility of identifying a biological signature for burnout in light of global research on burnout-depression overlap.
\end{abstract}

Orosz et al. (2017) examined the question of whether burnout can be distinguished from depression based on three indicators, heart rate variability, brain-derived neurotrophic factor, and hippocampal volume. The authors did not find conclusive evidence that burnout is biologically distinguishable from depression on these bases and suggested that more integrative research is needed to disentangle burnout from depression. In this commentary, we discuss seldom-noticed methodological problems affecting biological research on burnout and depression and make recommendations to overcome the limitations of past studies conducted in this area.

First, biological research on burnout and depression would benefit from a subtyping of depressive syndromes (American Psychiatric Association $[\mathrm{APA}], 2013)$. For instance, melancholic and atypical ${ }^{1}$ forms of depression have been associated with opposite autonomic and neuroendocrine profiles (Bianchi et al., 2015a; Gold and Chrousos, 2002; Lamers et al., 2013). Whereas depression with melancholic features has been linked to insomnia, aphagia, sympathetic hyperactivity, and hypercortisolism, depression with atypical features has been linked to hypersomnia, hyperphagia, sympathetic hypoactivity, and hypocortisolism. Such differences are likely to influence variables such as heart rate variability-given that cardiac activity is controlled by the autonomic nervous system-and hippocampal volume-given that loss of hippocampal volume in depression is thought to be partly cortisolinduced (Sapolsky, 2001). Not considering these differences is therefore problematic and can lead to misleading conclusions in research on burnout-depression overlap. Emblematically, the often-advanced argument that burnout is distinct from depression because burnout involves hypocortisolism whereas depression involves hypercortisolism (Marchand et al., 2014; Toker et al., 2012) falls apart as soon as atypical depression is introduced into the picture (Bianchi et al., 2015a).

Second, biological research on burnout-depression overlap is undermined by the absence of a consensual conceptualization and operationalization of burnout (Bianchi et al., 2015a, 2015b; Kristensen et al., 2005; Weber and Jaekel-Reinhard, 2000). This problem is obvious in the studies reviewed by Orosz et al. (2017), in which burnout was assessed based on a variety of definitions and measures. This heterogeneity makes between-study comparisons difficult and may explain the inconsistencies found by Orosz et al. (2017) in the literature dedicated to the biology of burnout. Interestingly, while burnout has been generally defined as a combination of exhaustion, cynicism, and loss of

\footnotetext{
Our commentary concerns the following article: Orosz, A., Federspiel, A., Haisch, S., Seeher, C., Dierks, T., Cattapan, K., 2017. A biological perspective on differences and similarities between burnout and depression. Neurosci. Biobehav. Rev. 73, 112-122.

* Corresponding author at: University of Neuchâtel, Institute of Work and Organizational Psychology, Émile-Argand 11, 2000 Neuchâtel, NE, Switzerland.

E-mail address: renzo.bianchi@unine.ch (R. Bianchi).

${ }^{1}$ The term atypical "does not connote an uncommon or unusual clinical presentation" (APA, 2013 p. 186). Depression with atypical features is a frequently encountered form of depression (Blanco et al., 2012; Matza et al., 2003).
} 
professional efficacy (Maslach et al., 1996), biological research on burnout-depression overlap has relied heavily on a different definition of burnout (see Bianchi et al., 2015a), a definition according to which burnout combines physical fatigue, cognitive weariness, and emotional exhaustion (Shirom and Melamed, 2006). In order to overcome the current climate of definitional confusion attached to burnout, establishing a commonly shared, clinically valid diagnosis for burnout should be considered a top priority. Today, research on the biology of burnout seems to be caught in a vicious circle. Indeed, while biologically-driven research is intended to better characterize burnout, burnout would need to be better characterized in order for biologicallydriven research to progress. The establishment of binding diagnostic criteria for burnout could put an end to that paradoxical situation.

To conclude, we note that Orosz et al.'s (2017) findings are in fact consistent with the increasingly-supported view that burnout constitutes a depressive condition and not a distinct entity (Ahola et al., 2014; Bianchi et al., 2015c; Bianchi et al., 2017a; Bianchi et al., 2017b; Wurm et al., 2016). In recent years, empirical evidence for burnoutdepression overlap has accumulated along various lines of research. Burnout has been found to overlap with depression in terms of etiology, reported symptoms, behaviorally-indexed processing of emotional information, allostatic load, and dispositional correlates and predictors (e.g., neuroticism, pessimistic explanatory style, interpersonal rejection sensitivity). In addition, burnout and depression have been shown to result in similar occupational outcomes, such as impaired work performance, absenteeism, and job turnover (see Bianchi et al., 2016). At a theoretical level, the claim that burnout is distinct from depression has been found to be rooted in (a) a neglect of the stress-depression causal relationship and (b) a defective coordination of dimensional and categorical approaches to depression in burnout research (Bianchi et al., 2017a; Bianchi et al., 2017b). In light of global research on burnoutdepression overlap, the absence of a distinctive biological signature for burnout appears as an expected, rather than a surprising, result.

\section{Conflict of interest}

None declared.

\section{References}

Ahola, K., Hakanen, J., Perhoniemi, R., Mutanen, P., 2014. Relationship between burnout and depressive symptoms: a study using the person-centred approach. Burn Res. 1 (1), 29-37.

American Psychiatric Association, 2013. Diagnostic and Statistical Manual of Mental Disorders, fifth ed. American Psychiatric Association, Washington.

Bianchi, R., Schonfeld, I.S., Laurent, E., 2015a. Burnout-depression overlap: a review. Clin. Psychol. Rev. 36, 28-41.

Bianchi, R., Schonfeld, I.S., Laurent, E., 2015b. Burnout: absence of binding diagnostic criteria hampers prevalence estimates. Int. J. Nurse Stud. 52 (3), 789-790.

Bianchi, R., Schonfeld, I.S., Laurent, E., 2015c. Is it time to consider the burnout syndrome a distinct illness? Front. Public Health 3, 158.

Bianchi, R., Verkuilen, J., Brisson, R., Schonfeld, I.S., Laurent, E., 2016. Burnout and depression: label-related stigma help-seeking, and syndrome overlap. Psychiatry Res. 245, 91-998.

Bianchi, R., Schonfeld, I.S., Laurent, E., 2017a. Physician burnout is better conceptualised as depression. Lancet 389, 1397-1398.

Bianchi, R., Schonfeld, I.S., Vandel, P., Laurent, E., 2017b. On the depressive nature of the "burnout syndrome": a clarification. Eur. Psychiatry 41, 109-110.

Blanco, C., Vesga-Lopez, O., Stewart, J.W., Liu, S.M., Grant, B.F., Hasin, D.S., 2012. Epidemiology of major depression with atypical features: results from the National Epidemiologic Survey on Alcohol and Related Conditions (NESARC). J. Clin. Psychiatry 73 (2), 224-232.

Gold, P.W., Chrousos, G.P., 2002. Organization of the stress system and its dysregulation in melancholic and atypical depression: high vs low CRH/NE states. Mol. Psychiatry 7 (3), 254-275.

Kristensen, T.S., Borritz, M., Villadsen, E., Christensen, K.B., 2005. The Copenhagen Burnout Inventory: a new tool for the assessment of burnout. Work Stress 19 (3), $192-207$.

Lamers, F., Vogelzangs, N., Merikangas, K.R., de Jonge, P., Beekman, A.T.F., Penninx, B.W.J.H., 2013. Evidence for a differential role of HPA-axis function, inflammation and metabolic syndrome in melancholic versus atypical depression. Mol. Psychiatry 18 (6), 692-699.

Marchand, A., Durand, P., Juster, R.P., Lupien, S.J., 2014. Workers' psychological distress, depression, and burnout symptoms: associations with diurnal cortisol profiles. Scand. J. Work Environ. Health 40 (3), 305-314.

Maslach, C., Jackson, S.E., Leiter, M.P., 1996. Maslach Burnout Inventory Manual, third ed. Consulting Psychologists Press, Palo Alto.

Matza, L.S., Revicki, D.A., Davidson, J.R., Stewart, J.W., 2003. Depression with atypical features in the national comorbidity survey: classification, description, and consequences. Arch. Gen. Psychiatry 60 (8), 817-826.

Orosz, A., Federspiel, A., Haisch, S., Seeher, C., Dierks, T., Cattapan, K., 2017. A biological perspective on differences and similarities between burnout and depression. Neurosci. Biobehav. Rev. 73, 112-122.

Sapolsky, R.M., 2001. Depression, antidepressants, and the shrinking hippocampus. Proc. Natl. Acad. Sci. U. S. A. 98 (22), 12320-12322.

Shirom, A., Melamed, S., 2006. A comparison of the construct validity of two burnout measures in two groups of professionals. Int. J. Stress Manage. 13 (2), 176-200.

Toker, S., Melamed, S., Berliner, S., Zeltser, D., Shapira, I., 2012. Burnout and risk of coronary heart disease: a prospective study of 8838 employees. Psychosom. Med. 74 (8), 840-847.

Weber, A., Jaekel-Reinhard, A., 2000. Burnout syndrome: a disease of modern societies? Occup. Med. 50 (7), 512-517.

Wurm, W., Vogel, K., Holl, A., Ebner, C., Bayer, D., Morkl, S., Szilagyi, I.S., et al., 2016. Depression-burnout overlap in physicians. PLoS One 11 (3), e0149913. 